\title{
Seasonal distribution in conceptions achieved by artificial insemination by donor
}

\author{
E C Paraskevaides, G W Pennington, S Naik
}

\begin{abstract}
The distribution of conceptions after artificial insemination from a donor was studied in 259 conceptions at an artificial insemination clinic and found to be seasonal. Conception was not influenced by the number of donors or patients attending the clinic, the frequency of inseminations, or medical skill. Conception was more common from early winter until early spring (October to March) with a peak in November. As variables such as frequency of intercourse and ovulation were irrelevant in these women and highest sperm counts occur from February to March these results suggested a seasonal variation in the quality of the ovulated egg or endometrial receptivity.

The waste of eggs after ovulation (or preimplantation conceptuses) at specific times of the year has implications in the treatment of infertility, particularly for in vitro fertilisation and gamete intrafallopian transfer.
\end{abstract}

\section{Introduction}

A seasonal distribution in rates of natural conception has been documented in several geographic populations. Possible hypotheses to explain this abound. In pregnancies achieved by donor insemination the male factor is iatrogenically controlled, ovulation is closely monitored, and the frequency of intercourse has no influence on the rate of conception. We retrospectively surveyed pregnancies achieved by artificial insemination from a donor to establish whether the month of insemination influenced the number of pregnancies achieved. We also looked at other factors

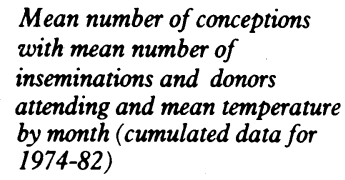

\section{Department of}

Gynaecology, North

Manchester General

Hospital, Manchester

E C Paraskevaides, FRCSED, registrar

Regional Choriocarcinoma and Infertility Centre, Jessop Hospital for Women, Sheffield G W Pennington, FRCOG, director

S Naik, DA, associate specialist

Correspondence to: $\mathrm{Mr}$ E C Paraskevaides, 17 Diglee Road, Stockport SK12 7PW.
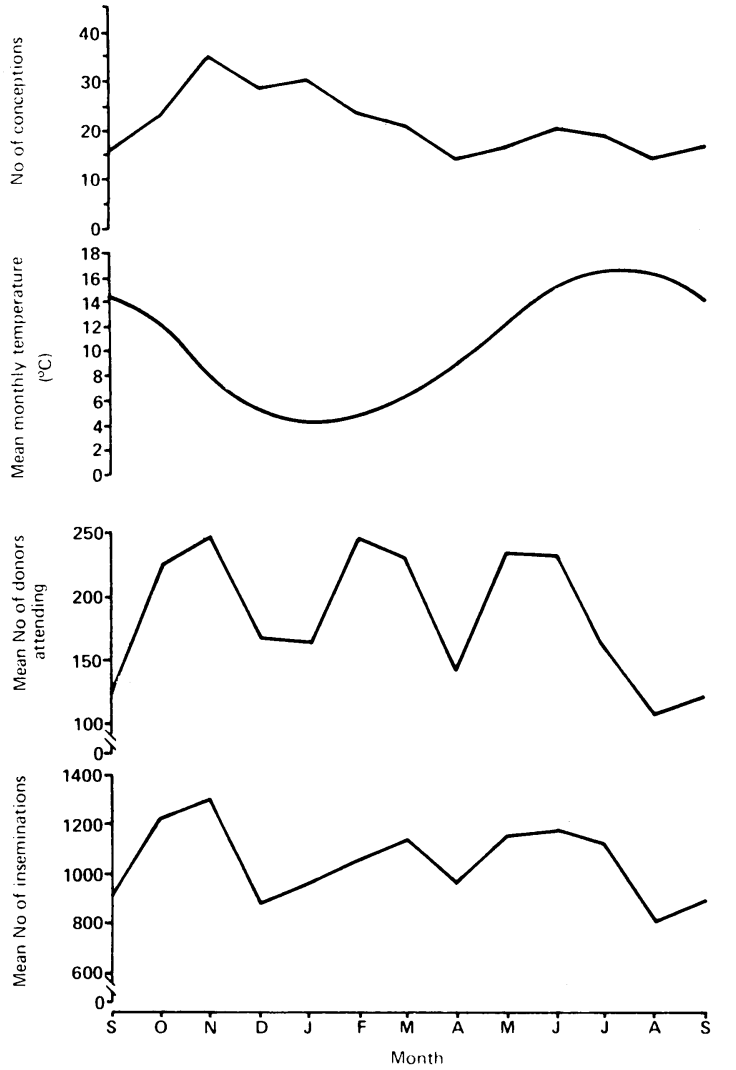

that might contribute, such as the seasonal variation in temperature, the numbers of donors and patients attending at any particular time, and the degree of medical skill available.

\section{Patients and methods}

Women seen at the insemination (donor) clinic at Jessop Hospital were given a thorough investigation of infertility; the fallopian tubes were confirmed to be patent by either hysterosalpingography or laparoscopy and insufflation. Any women found to be infertile were eliminated from the study. The number of patients attending for insemination was calculated for each month for 1974-82. The number of donors attending each month was also recorded. Seasonal variation in the quality of semen was examined by monthly analysis of semen from six donors.

Insemination was carried out with fresh or stored semen on two occasions each month at the presumed time of ovulation. When the number of donors attending was high fresh semen was used on both occasions; when it was low fresh semen was used on only one occasion. The administration of two cycles of fresh semen was therefore distributed in the same manner as the number of attending donors (see figure). After semen had been given ovulation was verified by measurement of the urinary pregnanediol concentration on days 20 and 22 of the menstrual cycle.

Before insemination each patient's menstrual cycle had been examined in detail by serial estimations of 24 hour urinary follicle stimulating hormone, luteinising hormone, oestriol, and pregnanediol concentrations at two day intervals. The presumed day of ovulation had thus been determined. After absence of menstruation pregnancy was confirmed by urinary assay of human chorionic gonadotrophin and ultrasonography after six weeks' amenorrhoea.

The total number of conceptions occurring in each month together with possible factors influencing conception were examined. Empirical cumulated distribution functions were calculated from the frequency distributions for insemination and conception. Kuiper's non-parametric two sample test was used to analyse the differences in distribution functions. ${ }^{\prime}$

The mean monthly temperatures for $1974-82$ were obtained from the Manchester weather centre.

\section{Results}

From 1974 to 1982 data on 259 conceptions were available. The figure shows the cumulated incidence of conceptions each month with a notable increase in the rate from October to March, which peaked in November. The figure also shows the average mean monthly temperatures. The mean temperature during the six months April to September was more than twice that during October to March. More conceptions seemed to occur during the period of lower temperatures.

\section{NUMBER OF DONORS ATTENDING}

Most donors used for artificial insemination in this clinic are university students, and we expected the number of attendances to fall during university holidays. The figure shows the mean number of donors 
attending each month. Fewer donors attended in March to April (Easter holiday), June to August (summer), and December to January (Christmas and new year). The main peak of conceptions was between October and January, when both high and low numbers of donors attended.

\section{NUMBER OF INSEMINATIONS}

As the rate of conception may be influenced by the number of inseminations performed each month this factor was also considered (figure). We found that though there was a concomitant peak in the number of inseminations and the rate of conception from September to November this did not continue during December to January. An additional peak in the number of inseminations occurred during the summer months without any associated rise in the rate of conception. Kuiper's test showed that the distributions of insemination and conception were significantly different $\left(\mathrm{Vu}_{1}^{\star}=1.988 ; \mathrm{p}=0.025\right)$.

The table shows mean number of inseminations per conception for each month. The number varied considerably and was lowest from November to February, precisely at the time when the number of conceptions increased. Thus the number of conceptions obtained was not influenced by the number of inseminations in any particular month.

Mean numbers of inseminations and conceptions by month of year, 1974-82

\begin{tabular}{lccc}
\hline Month & Inseminations & Conceptions & $\begin{array}{c}\text { Inseminations/ } \\
\text { conception }\end{array}$ \\
\hline January & 955 & 30 & 32 \\
February & 1060 & 23 & 46 \\
March & 1141 & 21 & 54 \\
April & 948 & 14 & 68 \\
May & 1152 & 16 & 72 \\
June & 1175 & 20 & 59 \\
July & 1131 & 19 & 60 \\
August & 806 & 14 & 58 \\
September & 893 & 16 & 56 \\
October & 1222 & 23 & 53 \\
November & 1282 & 35 & 37 \\
December & 864 & 28 & 31 \\
\hline Total & 12629 & 259 & 49 \\
\hline
\end{tabular}

\section{SKILL OF MEDICAL STAFF}

Most inseminations were carried out by senior house officers, who worked at the centre for six months from either 1 August or 1 February. The largest number of conceptions might be expected to occur in the latter half of their tenure - that is, November to January and May to July - when they would be more experienced. No obvious pattern between these two periods was seen; one showed a high rate of conception and the other the opposite.

\section{QUALITY OF SEMEN}

The seasonal variation in conception might have been due to a seasonal variation in quality of semen. In samples of semen from the same donor examined at different times of the year maximum sperm counts occurred between February and May (unpublished results).

\section{Discussion}

In animals there is a pronounced seasonal change in reproduction. In ewes the length and time of the breeding season are determined by photoperiod, which affects the release of gonadotrophin. ${ }^{4}$ Wild rabbits tend to breed in spring, when the females' oestrogen concentrations are higher, and produce larger litters. Fluctuations in pituitary or pineal output might result in this variation."

Seasonal variation in rates of natural conception in women is well documented. The peak lasts from early winter to early spring. ${ }^{67}$ We found that conceptions resulting from artificial insemination were similarly distributed and that this distribution was not influenced by the number of donors and women attending the clinic, the total number of inseminations carried out, or the skill of the doctor.

Several theories have been proposed to explain the seasonal variation in natural conception in women. In developing societies rates of infection, dietary intake, reliability of food supplies, and seasonal variation in fecundity induced by malaria have all been implicated. ${ }^{8}$ Sociocultural factors, movement due to seasonal employment, and climacteric variations have also been suggested. ${ }^{10}$ Seasonal birth rates have also been recorded in Labrador Eskimos. ${ }^{11}$ In Western societies, where environmental factors such as those stated above are of little relevance, ${ }^{12}$ seasonal variation in natural conception is still seen.

This variation must be due to seasonal variation in one or more of five variables: $(a)$ the frequency of intercourse; $(b)$ the rate of ovulation; $(c)$ the quality of semen; $(d)$ the quality of the egg after ovulation or the preimplantation conceptus; and (e) endometrial receptivity. Several of these variables were controlled in our study. Frequency of intercourse is not relevant as insemination was by donor semen administered on two occasions during each cycle and the women's partners were infertile. Similarly the rate of ovulation was unimportant as only the cycles of treatment in which ovulation was confirmed endocrinologically were included. Seasonal variation in the quality of semen is well documented, with maximum sperm counts and density and semen volume at the end of winter and beginning of spring (February to March). ${ }^{23}$ Our results showed a distinct increase in rates of conception in early winter-that is, before the improvement in the quality of semen. By exclusion, therefore, we suggest that there is seasonal variation in the quality of the ovulated egg or endometrial receptivity, or both, and that the time of highest quality is early winter.

The possibility of great waste of ovulated eggs and preimplantation conceptuses at specific times of the year has important implications for in vitro fertilisation and gamete intrafallopian transfer as well as infertility in general. Seasonal studies of the biochemistry of human germ cells may show important indicators of potential fertility. Similarly, seasonal pharmacological studies of human endometrium and myometrium, as well as pituitary and pineal output, may increase understanding of infertility.

We thank $\mathrm{Mr}$ Alan Gibbs, medical statistician at Manchester Medical School, for his help.

Mardia KV. Statistics of directional data. London: Academic Press, 1972.

2 Spira A. Seasonal variations in sperm characteristics. Arch Androl 1984;12.

23-8.
3 Tjoa WS, Smolensky MH, Hsi BP, Steinberger E, Smith KD. Circannual rhythm in human sperm count revealed by serially independent sampling. Fertil Steril 1982;38:454-9.

4 Montgomery GW, Hawker $\mathrm{H}$. Seasonal reproduction in ewes selected on seasonal changes in wool growth. $\mathcal{F}$ Reprod Fertil 1987;79:207-13.

5 Stern JE, Vaughan GL. Seasonal changes in oestrogen receptor affinity in the domestic rabbit, Oryctolagus cuniculus. $\mathcal{F}$ Reprod Fertil 1987;79:15-20.

6 Odegard $\mathrm{O}$. Season of birth in the population of Norway, with particular reference to the September birth maximum. Br $\mathcal{F}$ Psychiatry 1977;131 $339-44$.

7 Mathers CD, Harris RS. Seasonal distribution of births in Australia. Int $\mathcal{F}$ Epidemiol 1983;12:326-31.

8 Bantje $\mathrm{H}$. Seasonability of births and birthweights in Tanzania. Soc Sci Med 1987;24:733-9.

9 Ayeni O. Seasonal variation of births in rural southwestern Nigeria. Int $\mathcal{F}$ Epidemiol 1986;15:91-4.

10 Levy V. Seasonal fertility cycles in rural Egypt: behavioural and biological linkages. Demography 1986;23:13-30.

11 Ehrenkranz JR. Seasonal breeding in humans: birth records of the Labrador Eskimo. Fertil Steril 1983;40:485-9. Eskimo. Fertil Steril 1983;40:485-9.
12 James WH. Seasonality in twin and triplet births. Ann Hum Biol 1980;7:163-
75 .

(Accepted 23 August 1988) 